\title{
When Athlete's Foot, Commonly Evoked By T.Pedis, Is Accompanied By Bacterial Assaults, It Is Advisable To Use Drastic Dosages Of Antimycotics, Neem Oil And Silver Citrate.
}

\author{
Texia Research ${ }^{1}$, Lorenzo Martini² \\ ${ }^{1}$ Texia Innovazione Dermatologica-Turin, ${ }^{2}$ Department of Pharmaceutical Biotechnologies University of Siena
}

\begin{abstract}
Intention of our study is to demonstrate that when Athlete's foot is not well treated or neglected at all, many bacterial attacks may occur, especially by Staphylococcus aureus, especially in persons who for sake of their hard job have to wear amphibious work boots in summertim. The disease becomes more and more severe and important and thus we have discovered that instead of using antimycotic agents only (because it is evident that there is even a microbial co-existence), it is better to employ massive dosages of antimycotic agents and Neem oil and Silver citrate, apt to combat Staphylococci.
\end{abstract}

Keywords: Athlete's foot, Tinea pedis,Staphylococcus aureus, Neem oil, Silver citrate.

\section{Background}

Chalmer (1) in 1972 referred that in 348 individuals examined in a Civic Hospital suffering from Athlete's foot, $40.8 \%$ of them was affected by Tinea pedis. The remnant of patients showed the presence of Tricophyton interdigitale (50\%), Tricophyton rubrum (26\%), Epidermophyton floccosum (0.7\%), bacteria Gram $+(4.1 \%)$, bacteria Gram+ and Gram- $(11.7 \%)$ and other bacteria not well identifiable $(7.5 \%)$.

This means that $23.3 \%$ of a diagnosed Athletes'foot is accompanied by bacterial affections (especially Staphylococcus aureus) (2) and all these cases corresponded to people who had not treated exhaustively the fungal infection since the very first occurrence.

Generally sportmen suffer from Athlete's foot and begin to treat this malaise using antifungal products acquired in pharmacies or drugstores, but there is an avalanche of individuals who for sake of their job and cause of lack of time, do not treat the very first occurrence of the fungal infection, so, after some weeks, bacterial infections occur and the problem becomes severe and difficult to be treated.

The symptoms are the following: itching, stinging, and burning between the toes itching, stinging, and burning on the soles of the feet blisters on the feet that itch cracking and peeling skin on the feet, most commonly between the toes and on the soles dry skin on the soles or sides of the feet raw skin on the feet discolored, thick, and crumbly toenails toenails that pull away from the nail bed. Generally these individuals are women and men who are forced to wear amphibian work boots, sometimes for 8-12 hours continuously, in winter or in summer (foresters, fire-fighters, security guards, some special cops and others).

When the disease is dogged, precautions and preventions as foot care and hygiene (foot-baths,footpowders, sprays or emulsions) result utterly unuseful. Intention of our study is to compare the efficacy of an ancient recipe (Dr.Castellani's Pediluvium; a solution of tartaric acid 10\% and sodium thiosulfate 5\% to be used as foot-bath) that boasts of the triple activities: keratolytic,antimycotic and antibacterial in some volunteers and indeed the alternate usage of two new emulsions, the former that guarantees an antimycotic function and the latter an antibacterial ability (owing to the massive presence of Melia azadirachta oil and Silver citrate) $(3,4)$ on another panel group of people who suffer from Athlete's foot with bacterial assault. (identified as Staphylococcus aureus).

The two creams contained:

the former:

Clotrimazole,

Ciclopirox Olamine,

Urea,

Panthenol,

Hydrolized Soy Protein,

Zinc Gluconate,

Tridecyl Salicylate,

Hydrolized Soy Protein

And The Latter:

Cera Alba

Ceresin 


\section{Bisabolol}

Melia Azadirachta Seed Oil

Sodium Hyaluronate

Silver Citrate

Chloroxylenol

\section{Materials and Methods}

We have recruited 6 (six) volunteers (one security guard female, two security guards male, one fireman, two foresters, one emergency physician) and we have shared the 6 people in two panel groups:

A) Security guard male

B) Fireman

C) Forester

And

D) Security guard female

E) Forester

F) Emergency physician

And we have treated the first group with the Castellani's Pediluvium till all the symptoms of Athlete's foot disappear, evaluating the successes obtianed by a scale that goes from nil to 10 during the days of treatment, and we have treated the second group mixing together the two emulsions (the trade marks are reported in section "Aknowledgements"). We have continued the applications of the two remedies on the two panel groups until the final remission (nine days for the first panel group, 4-5 days for the first panel group).

\section{Results:}

Here follow 6 tables where all the scores (both subjective and objective) are plotted during the 9 days of treatment in both panel groups.

In Table I it is possible to observe the scores for nil to 10 the patients themselves attributed to the feeling of their symptoms (and the score has been approved by our objective examination).

Table I: results of ameliorating of the malaise of Case A of the first panel group

\begin{tabular}{|l|l|}
\hline Progressive number of days of treatment & Score (subjective of the patient and objective of the investigators) \\
\hline 1 & 10 \\
\hline 2 & 8 \\
\hline 3 & 7 \\
\hline 4 & 7 \\
\hline 5 & 6 \\
\hline 6 & 6 \\
\hline 7 & 5 \\
\hline 8 & 3 \\
\hline 9 & 0 \\
\hline
\end{tabular}

Table II: results of ameliorating of the malaise of Case B of the first panel group

\begin{tabular}{|l|l|}
\hline Progressive number of days of treatment & Score (subjective of the patient and objective of the investigators) \\
\hline 1 & 10 \\
\hline 2 & 9 \\
\hline 3 & 9 \\
\hline 4 & 8 \\
\hline 5 & 7 \\
\hline 6 & 7 \\
\hline 7 & 6 \\
\hline 8 & 4 \\
\hline 9 & 0 \\
\hline
\end{tabular}

Table III: results of ameliorating of the malaise of Case $\mathrm{C}$ of the first panel group

\begin{tabular}{|l|l|}
\hline Progressive number of days of treatment & Score (subjective of the patient and objective of the investigators) \\
\hline 1 & 10 \\
\hline 2 & 8 \\
\hline 3 & 6 \\
\hline 4 & 5 \\
\hline 5 & 3 \\
\hline 6 & 2 \\
\hline 8 & 2 \\
\hline 9 & 1 \\
\hline
\end{tabular}


When Athlete's foot, commonly evoked by T.pedis, is accompanied by bacterial assaults, it is ..

Table IV: results of ameliorating of the malaise of Case D of the second panel group

\begin{tabular}{|l|l|}
\hline Progressive number of days of treatment & Score (subjective of the patient and objective of the investigators) \\
\hline 1 & 10 \\
\hline 2 & 6 \\
\hline 3 & 4 \\
\hline 4 & 2 \\
\hline 5 & 1 \\
\hline 6 & 0 \\
\hline 7 & 0 \\
\hline 8 & 0 \\
\hline 9 & 0 \\
\hline
\end{tabular}

Table V: results of ameliorating of the malaise of Case E of the second panel group

\begin{tabular}{|l|l|}
\hline Progressive number of days of treatment & Score (subjective of the patient and objective of the investigators) \\
\hline 1 & 10 \\
\hline 2 & 8 \\
\hline 3 & 4 \\
\hline 4 & 3 \\
\hline 5 & 1 \\
\hline 6 & 0 \\
\hline 7 & 0 \\
\hline 8 & 0 \\
\hline 9 & 0 \\
\hline
\end{tabular}

Table VI: results of ameliorating of the malaise of Case F of the second panel group

\begin{tabular}{|l|l|}
\hline Progressive number of days of treatment & Score (subjective of the patient and objective of the investigators) \\
\hline 1 & 10 \\
\hline 2 & 7 \\
\hline 3 & 4 \\
\hline 4 & 3 \\
\hline 5 & 1 \\
\hline 6 & 0 \\
\hline 8 & 0 \\
\hline 9 & 0 \\
\hline
\end{tabular}

\section{Results}

We can assert with no doubt that the first panel group, treated by the Castellani'sPediluvium (a saturated solution of tartaric acid and sodium thiosulfate) necessitated nine days for a complete remission and almost no sign of ameliorating of the disease was evident till the end of the treatment.

The three components of the second group showed bright results after the 4th-5th day, depending on the severity of the bacterial infection they suffered from.

\section{Discussions and conclusions:}

It is indisputable that high dosages of antimycotic agents mixed with Melia azadirachta seed oil (Neem) and Silver citrate (that actas strongest antimicrobic) are more efficient than antic and/or antique remedies.

\section{Acknowledgments}

The study has been conducted owing to the two novel cosmetic products by Texia s.r.l., called Sporax Fluid and Bactrene.

[1]. Chalmers L; Manuf.Chem. 1972, 43 (1),33

\section{References}

[2]. Al Hasan M, Fitzgerald SM, Saoudian M, Krishnaswamy G; Dermatology for the practicing allergist: Tinea pedis and its complications; 2004:Clin Mol Allergy. ; 2: 5.

[3]. Khan AV, * Ahmed QU, Mir MR, Shukla I, Khan AA:Antibacterial efficacy of the seed extracts of Melia azedarach against some hospital isolated human pathogenic bacterial strains;2011:Asian Pac J Trop Biomed. ; 1(6): 452-455.

[4]. Jung WK, Koo HC, Kim, KW, Shin S, Kim SH, Park YH;Antibacterial Activity and Mechanism of Action of the Silver Ion in Staphylococcus aureus and Escherichia coli; 2008:-Appl Environ Microbiol;; 74(7): 2171-2178. 